\title{
Post-evaluation of tourist roads based on new concept of road design and application of interval approximation method for quantitative evaluation
}

\author{
Zhang Yonghong \\ CCCC Infrastructure Maintenance Group CO., LTD, Beijing, China \\ 43968490@qq.com
}

Keywords: post-evaluation, tourist road, harmony, interval approximation

\begin{abstract}
In order to better promote the demonstration effect of tourism roads with the assistance of post-evaluation of projects, this paper establishes the tourist road harmonious evaluation system, consisting of the harmony of road area, the harmony between people and road, the harmony of the external environment of the road as the core of indicators for the above-mentioned evaluation system, after in-depth study of the concept concerning harmony of tourist road. Furthermore, this paper adopts an approach based on interval approximation to evaluate the harmony of tourist road, and carries out post-evaluation of typical demonstration tourism road in Hebei Province, which further validates the practicability of tourist road harmony assessment methods based on interval approach.
\end{abstract}

\section{Introduction}

Tourist road is a kind of road which has remarkable characteristics and typical characteristics to itself and the landscape along the route, and has strong ornamental value, which mainly highlights its tourism service function. With the goal of building a beautiful China, tourist roads will play a greater role as a "window" and a gateway to beauty.

In 2002, the Ministry of Transport (abbreviated as MOT) and the government of Sichuan Province jointly organized relevant institutions to carry out the reconstruction project of the Sichuan-Jiuji Road (Chuanzhusi- Jiuzhaigou tourism road) as a demonstration project. The success was achieved with good social effects. Feng Zhenlin, Vice Minister of Transport, proposed "six persistence and six set-ups" as the theoretical core of road survey and design work in the new period at the 2004 National Survey and Design Conference, thus putting forward new requirements for road survey and design. At the same time, the Department of Road of MOT and the Planning and Research Institute of MOT have jointly deepened the above-mentioned core theory, and put forward a new concept of road design, illustrated by the harmony ideas of "flexibility, tolerance and innovation" ${ }^{[1]}$.With this guidance, more than 40 typical demonstration projects have been carried out, covering 31 provinces, municipalities directly under the Central Government and autonomous regions throughout China. Through demonstration of results, and promotion of large areas, these projects have been gradually completed, and achieved significant results. Therefore, it is necessary to carry out the post-evaluation of landscape harmony for these typical demonstration projects, in 
order to summarize successful experiences and shortcomings in practical projects, and provide a platform for the new design ideas to be integrated into the construction of tourist roads on a larger scale.

A successful tourist road is essentially a reflection of the harmony between its internal and external environment. Therefore, through the post-evaluation of the road harmony, one can have an overall understanding of the tourist road. It will lay a good foundation for protecting the natural and humanistic landscape resources along the road in the future. At the same time, it can also evaluate the impact of the ornamental value of these resources in the course of road construction.

\section{Thoughts on post-evaluation of tourism road harmony system}

Through the study of the concept of harmonization, the idea of tourist road post-evaluation can be determined in the following process: firstly, identify the evaluation target, and then systematically analyze the influencing factors to find out the evaluation items and determine the individual evaluation indicators. According to the actual environment, the evaluation order is arranged, and the weighting quantity is given to these indicators according to certain rules (reflecting the value status of each indicator in the system), thus forming an organic evaluation index system.

The system evaluation is aimed to judge the total value of the system, and the evaluation of the tourism road harmony is aimed to measure the degree of the tourism road harmony system to reach the goal. The output of the system is a value factor, which is called evaluation factor ${ }^{[2-6]}$. The total value of the system is determined by the interaction and interrelation of each evaluation factor of the system.

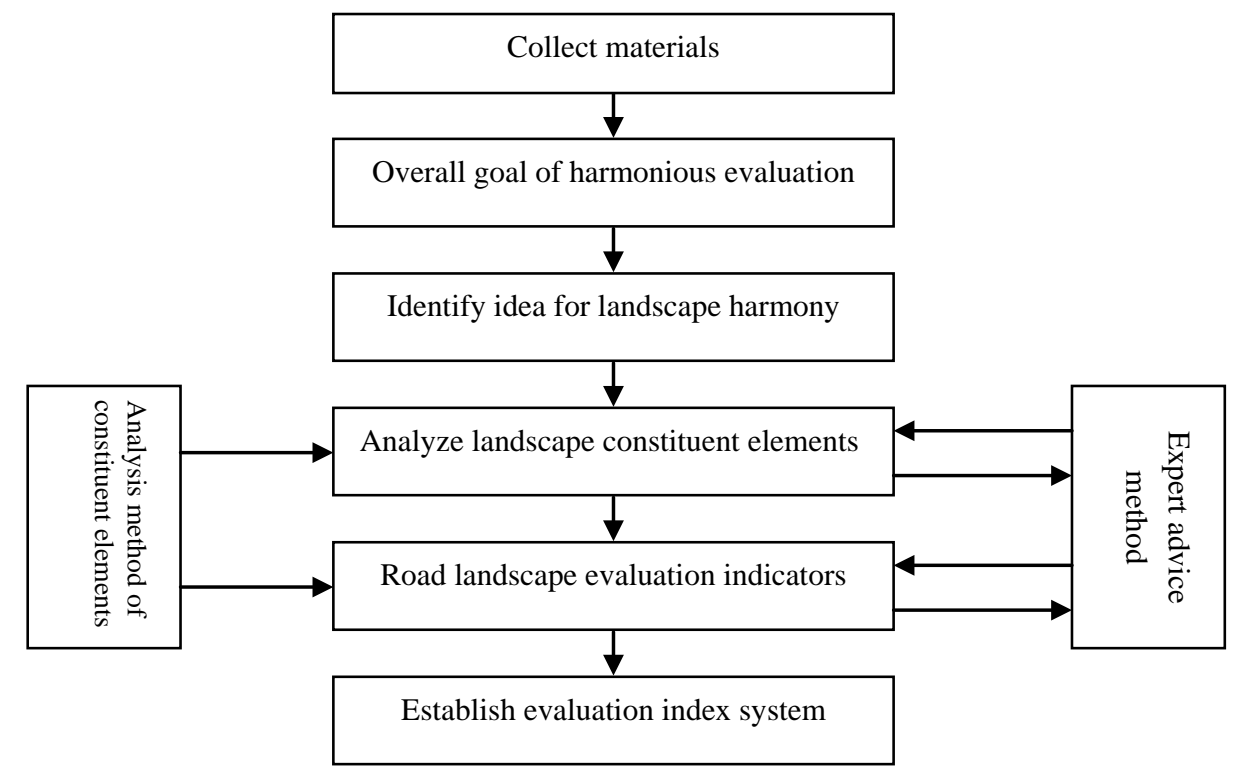

Fig.1. Flow chart of construction of tourism road evaluation index system

The evaluation of tourist road harmony is a multi-factor and highly comprehensive evaluation system. Based on the in-depth study of the new concept of road design, this paper sets up the harmonious evaluation system concerning tourist road and its internal and external system (see Fig.2.). The evaluation system includes three levels: the first layer (layer A) is the ultimate goal of the evaluation of tourist road harmony, which is tourist road harmonious degree; The second layer (layer B) is an analytical and evaluative indicator (assessment of projects), which is respectively based on the harmony of the landscape of the road area (aesthetics), the harmony between the road and its external environmental landscape (ecological environment) and the harmony between the 
tourist road and people (service function). The third layer (layer BII) is a descriptive evaluation index set (single index), which is the concrete expansion and analysis of each index of layer BI. Each evaluation element in layer BII can be further subdivided. The content of the framework can be added or subtracted according to the design content of the specific landscape project, or the weight value can be used to adjust the importance of each factor.

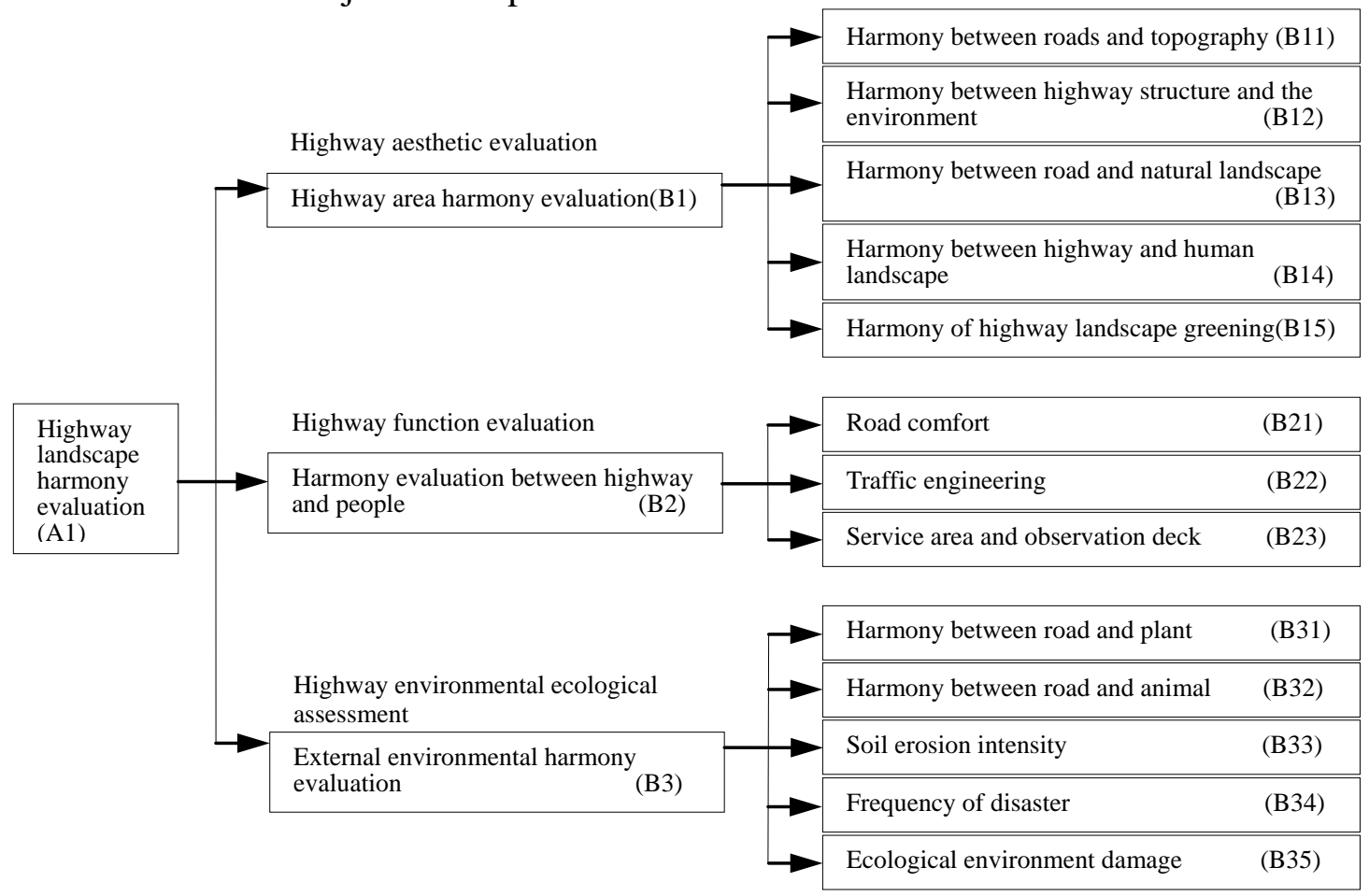

Fig. 2. Tourist road coordination assessment system

\section{Evaluation of tourist road harmony based on interval approximation}

As mentioned above, the evaluation of tourism roads is highly comprehensive, which is influenced by the interaction of various landscape elements. Therefore, it is an important task to choose effective evaluation method of tourist road to guide the protection, design and reconstruction of tourist road. In the past, many scholars used fixed value estimation to carry out comprehensive evaluation. However, because of the multiple index levels of tourist road evaluation, the specific indicators were different, due to the different emphasis of each project evaluation. The reliability and objectivity of evaluation data are poor by using the method of fixed value estimation. Therefore, this paper adopts the idea of overall approximation, defines the different grades of data and evaluation index as interval numbers, and uses interval numbers to reflect landscape harmony data. By using the interval number multi-attribute decision model to evaluate the tourism road harmony, it makes the tourism road harmonious evaluation more objective, scientific, and representative ${ }^{[7,8]}$.

\subsection{Harmony evaluation method based on interval approximation}

The interval number refers to the estimated range of indicators given by sub-samples under a certain degree of confidence. According to mathematical statistics, interval numbers can reflect the objectivity of the harmony evaluation of representative data, better than fixed values ${ }^{[8]}$. Generally speaking, if the random variable $\mathrm{x}$ follows the normal distribution of the parameter $\mu$ and $\sigma$, it can be recorded as $\mathrm{x} \sim \mathrm{N}(\mu, \sigma)$. According to the mathematical statistical knowledge, the bilateral confidence 
interval is as follow:

$$
\mu-u_{\alpha / 2} \times \sigma<x<\mu+u_{\alpha / 2} \times \sigma
$$

In the formula: $\alpha \_$significance level,

$1-\alpha-$ confidence level,

$u_{\alpha / 2} \_$critical value of the normal distribution of bilateral confidence intervals.

Among them, $u_{\alpha / 2}$ is called the guarantee rate coefficient(commonly represented by $Z \alpha$ ). The average value $\bar{x}$ and the standard deviation S respectively replace $\mu$ and $\sigma$ in the formula one. When the confidence probability is $95 \%, \quad u_{\alpha / 2}=1.96$, the number of intervals of measured data for each indicator can be expressed as:

$$
(\bar{x}-1.96 * S, \bar{x}+1.96 * S)
$$

\subsection{Establishment of multi-index interval number approximation decision-making model}

\subsubsection{Determination of tourist road harmony evaluation index system}

\subsubsection{Selection of evaluation indicators}

The harmonious evaluation system of tourist road in this paper is divided into three levels, namely, A, BI, and BII. A represents evaluation set: A= \{excellent, good, middle, inferior, poor . BIrepresents analytical evaluation index set: $\mathrm{BI}=\{$ excellent, good, middle, inferior, poor $\}$. B II and below layers are descriptive index sets: $\mathrm{BII}=\{$ excellent, good, medium, inferior, poor $\}$. According to the entropy method, the weights among the evaluation indexes of tourist road harmony can be determined $^{[9]}$.

\subsubsection{Basic descriptive indicators assessment}

The basic descriptive indicators are evaluated by a comprehensive scoring method, which is generally determined by expert scoring. For the main body of the evaluation, 3 or 10 persons can be selected. According to the average score (quantitative) or the evaluation attitude (qualitative), the percentage of people in each evaluation range is calculated. With regard to the issue of public attitude, multiple evaluation subjects can be investigated and the percentage of people with various evaluation attitudes can be counted as the basis of evaluation.

\subsubsection{Analytical index evaluation}

Analytical evaluation index set is $\left\{I_{1}, I_{2}, \cdots I_{n}\right\}$. As for the evaluation space $U$, the evaluation set is $\left\{C_{1}, C_{2}, \cdots C_{m}\right\} . \quad C_{k}(\mathrm{k}=1,2, \ldots, \mathrm{m})$ represents quality grade. The standard interval of single factor quality evaluation for analytical evaluation index is shown in Table 1.

Table 1. Classification of single index grades for evaluation of tourist roads

\begin{tabular}{|l|l|l|l|l|l|}
\hline index & \multicolumn{1}{|c|}{$I_{1}$} & \multicolumn{1}{|c|}{$I_{2}$} & \multicolumn{1}{c|}{$I_{3}$} & \multicolumn{1}{c|}{$I_{n}$} \\
\hline $\mathrm{C} 1$ & $S_{11}^{L}-S_{11}^{U}$ & $S_{12}^{L}-S_{12}^{U}$ & $S_{13}^{L}-S_{13}^{U}$ & $\ldots$ & $S_{1 n}^{L}-S_{1 n}^{U}$ \\
\hline $\mathrm{C} 2$ & $S_{21}^{L}-S_{21}^{U}$ & $S_{22}^{L}-S_{22}^{U}$ & $S_{23}^{L}-S_{23}^{U}$ & $\ldots$ & $S_{2 n}^{L}-S_{2 n}^{U}$ \\
\hline$\ldots \ldots$. & $S_{m 1}^{L}-S_{m 1}^{U}$ & $S_{m 2}^{L}-S_{m 2}^{U}$ & $S_{m 3}^{L}-S_{m 3}^{U}$ & $\ldots$ & $S_{m n}^{L}-S_{m n}^{U}$ \\
\hline $\mathrm{Cm}$ &
\end{tabular}




\subsubsection{Comprehensive evaluation of road harmony}

After processing the evaluation data of the basic descriptive indicators and analytical indicators, combined with the indicator weights, the assessment scale for the evaluation of the tourist road harmony is shown in Table 2, which can be counted according to the percentage system.

Table 2. Scale for the evaluation of tourist road harmony

\begin{tabular}{|l|l|l|l|l|c|}
\hline Score & $80 \sim 100$ & $60 \sim 80$ & $40 \sim 60$ & $20 \sim 40$ & $0 \sim 20$ \\
\hline Harmony evaluation scale & excellent & good & middle & inferior & poor \\
\hline
\end{tabular}

\subsubsection{The establishment of decision matrix and its standardization}

The indicator set for the road section (or project) to be evaluated is $\left.\left\{x_{01}^{L}, x_{01}^{U}\right],\left[x_{02}^{L}, x_{02}^{U}\right], \cdots,\left[x_{0 n}^{L}, x_{0 n}^{U}\right]\right\}$, and $x_{0 i}^{L} \leq x_{0 i}^{U}$. In order to facilitate the calculation of the analytical formula, the grade metrics ${ }^{\left[S_{i j}^{L}, S_{i j}^{U}\right]}$ in the single-index ranking table are expressed here as ${ }^{\left[x_{i j}^{L}, x_{i j}^{U}\right]}$. Then the decision matrix is as follows ${ }^{[10]}$ :

$$
\mathrm{X}=\left[\begin{array}{cccc}
{\left[x_{01}^{L}, x_{01}^{U}\right]} & {\left[x_{02}^{L}, x_{02}^{U}\right]} & \cdots & {\left[x_{0 n}^{L}, x_{0 n}^{U}\right]} \\
{\left[x_{11}^{L}, x_{11}^{U}\right]} & {\left[x_{12}^{L}, x_{12}^{U}\right]} & \cdots & {\left[x_{1 n}^{L}, x_{1 n}^{U}\right]} \\
{\left[x_{21}^{L}, x_{21}^{U}\right]} & {\left[x_{22}^{L}, x_{22}^{U}\right]} & \cdots & {\left[x_{2 n}^{L}, x_{2 n}^{U}\right]} \\
\vdots & \vdots & \vdots & \vdots \\
{\left[x_{m 1}^{L}, x_{m 1}^{U}\right]} & {\left[x_{m 2}^{L}, x_{m 2}^{U}\right]} & \cdots & {\left[x_{m n}^{L}, x_{m n}^{U}\right]}
\end{array}\right] \begin{gathered}
C_{X} \\
C_{1} \\
C_{2} \\
\vdots \\
C_{m}
\end{gathered}
$$

As for benefit index, it is necessary to make the following formula:

$$
y_{i j}^{L}=\frac{x_{i j}^{L}}{\sum_{i=1}^{m} x_{i j}^{U}}, y_{i j}^{U}=\frac{x_{i j}^{U}}{\sum_{i=1}^{m} x_{i j}^{L}} \quad \mathrm{i}=0,1,2, \ldots \mathrm{m} ; \mathrm{j}=1,2, \ldots \mathrm{n}
$$

The normalized interval number decision matrix is listed as follows:

$$
\mathrm{Y}=\left[\begin{array}{cccc}
{\left[y_{01}^{L}, y_{01}^{U}\right]} & {\left[y_{02}^{L}, y_{02}^{U}\right]} & \cdots & {\left[y_{0 n}^{L}, y_{0 n}^{U}\right]} \\
{\left[y_{11}^{L}, y_{11}^{U}\right]} & {\left[y_{12}^{L}, y_{12}^{U}\right]} & \cdots & {\left[y_{1 n}^{L}, y_{1 n}^{U}\right]} \\
{\left[y_{21}^{L}, y_{21}^{U}\right]} & {\left[y_{22}^{L}, y_{22}^{U}\right]} & \cdots & {\left[y_{2 n}^{L}, y_{2 n}^{U}\right]} \\
\vdots & \vdots & \vdots & \vdots \\
{\left[y_{m 1}^{L}, y_{m 1}^{U}\right]} & {\left[y_{m 2}^{L}, y_{m 2}^{U}\right]} & \cdots & {\left[y_{m n}^{L}, y_{m n}^{U}\right]}
\end{array}\right] \begin{gathered}
C_{X} \\
C_{1} \\
C_{2} \\
\vdots \\
C_{m}
\end{gathered}
$$

\subsubsection{Establishment of interval number decision evaluation matrix}

By using simple weighted average method $\mathrm{Y}$ and the weight vector for aggregation, the interval number decision evaluation matrix is obtained ${ }^{[9]}$.

$$
\mathrm{R}=\left[\begin{array}{cccc}
{\left[r_{01}^{L}, r_{01}^{U}\right]} & {\left[r_{02}^{L}, r_{02}^{U}\right]} & \cdots & {\left[r_{0 n}^{L}, r_{0 n}^{U}\right]} \\
{\left[r_{11}^{L}, r_{11}^{U}\right]} & {\left[r_{12}^{L}, r_{12}^{U}\right]} & \cdots & {\left[r_{1 n}^{L}, r_{1 n}^{U}\right]} \\
{\left[r_{21}^{L}, r_{21}^{U}\right]} & {\left[r_{22}^{L}, r_{22}^{U}\right]} & \cdots & {\left[r_{2 n}^{L}, r_{2 n}^{U}\right]} \\
\vdots & \vdots & \vdots & \vdots \\
{\left[r_{m 1}^{L}, r_{m 1}^{U}\right]} & {\left[r_{m 2}^{L}, r_{m 2}^{U}\right]} & \cdots & {\left[r_{m n}^{L}, r_{m n}^{U}\right]}
\end{array}\right] C_{X}
$$




$$
=\left[\begin{array}{cccc}
{\left[y_{01}^{L} \theta_{1}, y_{01}^{U} \theta_{1}\right]} & {\left[y_{02}^{L} \theta_{2}, y_{02}^{U} \theta_{2}\right]} & \ldots & {\left[y_{0 n}^{L} \theta_{n}, y_{0 n}^{U} \theta_{n}\right]} \\
{\left[y_{11}^{L} \theta_{1}, y_{11}^{U} \theta_{1}\right]} & {\left[y_{12}^{L} \theta_{2}, y_{12}^{U} \theta_{2}\right]} & \ldots & {\left[y_{1 n}^{L} \theta_{n}, y_{1 n}^{U} \theta_{n}\right]} \\
{\left[y_{21}^{L} \theta_{1}, x_{21}^{U} \theta_{1}\right]} & {\left[y_{22}^{L} \theta_{2}, y_{22}^{U} \theta_{2}\right]} & \ldots & {\left[y_{2 n}^{L} \theta_{n}, y_{2 n}^{U} \theta_{n}\right]} \\
\vdots & \vdots & \vdots & \vdots \\
{\left[y_{m 1}^{L} \theta_{1}, y_{m 1}^{U} \theta_{1}\right]} & {\left[y_{m 2}^{L} \theta_{2}, y_{m 2}^{U} \theta_{2}\right]} & \ldots & {\left[y_{m n}^{L} \theta_{n}, y_{m n}^{U} \theta_{n}\right]}
\end{array}\right] C_{1}
$$

\subsubsection{Decision criteria}

According to the statistical theory, the principle of decision-making is that the shorter the distance from the evaluation scheme to each grade of index, the closer they are to each other. Therefore, the level of the minimum distance is the evaluation level of the plan to be evaluated.

The formula for calculating the distance from $\mathrm{Cx}$ to each index of $\mathrm{Ci}$ is as follows:

$$
d_{i}=d\left(C_{x}, C_{i}\right)=\sqrt{\left(d_{i 1}^{+}\right)^{2}+\left(d_{i 1}^{+}\right)^{2}+\cdots+\left(d_{i n}^{+}\right)^{2}}
$$

In the formula, $d_{i j}^{+}=\max \left(\left|r_{0 j}^{L}-r_{i j}^{L}\right|,\left|r_{0 j}^{U}-r_{i j}^{U}\right|\right), \mathrm{i}=1,2, \ldots \mathrm{m} ; \mathrm{j}=1,2, \ldots \mathrm{n}$.

Determine the evaluation level of the scheme to be evaluated, according to the minimum value of $d_{i}$.

\section{Case studies on the harmony evaluation of tourist road based on interval approximation}

This section uses the aforementioned harmonized evaluation method for tourism roads to evaluate typical demonstration tourism roads that have been completed and opened to traffic,so as to verify the rationality of the index system and the applicability of the evaluation method.

\subsection{Screening of evaluation indicators}

By investigating the landscape environment along the road, the evaluation index and its main influencing factors are identified ${ }^{[10]}$, based on the landscape design scheme and suggestions of relevant professionals and experts, in reference to the assessment system of tourist road harmony in this paper. 
Table 3. Evaluation Indicators of a Certain Tourist Road

\begin{tabular}{|c|c|c|c|}
\hline Objective & $\begin{array}{l}\text { Evaluation } \\
\text { Item }\end{array}$ & Single Indicator & Main Influencing Factor \\
\hline \multirow{24}{*}{$\begin{array}{l}\text { Tourist } \\
\text { Road } \\
\text { Harmony } \\
\text { Evaluation } \\
\text { A1 }\end{array}$} & \multirow{12}{*}{$\begin{array}{l}\text { Road area } \\
\text { harmony } \\
\text { assessment } \\
\text { (B1) }\end{array}$} & \multirow{3}{*}{$\begin{array}{l}\text { Evaluation of harmony between } \\
\text { Road and topography (B11) }\end{array}$} & road subgrade earthwork volume \\
\hline & & & occupied area of road project \\
\hline & & & rationality of macro line design \\
\hline & & $\begin{array}{l}\text { Evaluation of Harmony between } \\
\text { Road Structure and Environment } \\
\text { (B12) }\end{array}$ & road structure coordination \\
\hline & & \multirow{3}{*}{$\begin{array}{l}\text { Evaluation of Harmony between } \\
\text { Road and Natural Landscape (B13) }\end{array}$} & landscape separation degree \\
\hline & & & landscape fragmentation \\
\hline & & & landscape diversity index \\
\hline & & \multirow{3}{*}{$\begin{array}{l}\text { Evaluation of Harmony between } \\
\text { Road and Human Landscape (B14) }\end{array}$} & landscape separation degree \\
\hline & & & landscape fragmentation \\
\hline & & & landscape diversity index \\
\hline & & \multirow{2}{*}{$\begin{array}{l}\text { Evaluation of Harmony of Tourist } \\
\text { Road Greening (B15) }\end{array}$} & vegetation coverage \\
\hline & & & $\begin{array}{l}\text { GBM engineering } \\
\text { implementation rate of road }\end{array}$ \\
\hline & \multirow{6}{*}{$\begin{array}{l}\text { People and } \\
\text { road harmony } \\
\text { assessment } \\
\text { (B2) }\end{array}$} & Pavement comfort evaluation (B21) & pavement flatness \\
\hline & & \multirow{3}{*}{$\begin{array}{l}\text { Traffic Engineering Evaluation } \\
\text { (B22) }\end{array}$} & $\begin{array}{l}\text { capacity assessment of } \\
\text { accessibility }\end{array}$ \\
\hline & & & $\begin{array}{l}\text { assessment of facilities along the } \\
\text { route }\end{array}$ \\
\hline & & & $\begin{array}{l}\text { evaluation of traffic signs and } \\
\text { markings }\end{array}$ \\
\hline & & \multirow{2}{*}{$\begin{array}{l}\text { Evaluation of service area and } \\
\text { observation deck (B23) }\end{array}$} & evaluation of the service area \\
\hline & & & evaluation of observation deck \\
\hline & \multirow{6}{*}{$\begin{array}{l}\text { Eternal } \\
\text { environment } \\
\text { harmony } \\
\text { assessment(B3) }\end{array}$} & $\begin{array}{l}\text { Harmony assessment of road and } \\
\text { plant (B31) }\end{array}$ & tree planting evaluation \\
\hline & & $\begin{array}{l}\text { Harmony Assessment of Road and } \\
\text { Animal (B32) }\end{array}$ & animal activity route evaluation \\
\hline & & Soil erosion intensity (B33) & soil erosion intensity \\
\hline & & $\begin{array}{l}\text { Disaster occurrence frequency } \\
\text { evaluation (B34) }\end{array}$ & disaster occurrence frequency \\
\hline & & \multirow[b]{2}{*}{ Ecological damage rating (B35) } & ecosystem stability \\
\hline & & & $\begin{array}{l}\text { rationality of construction } \\
\text { scheme }\end{array}$ \\
\hline
\end{tabular}

\subsection{Establishment of evaluation set}

\subsubsection{Establishment of evaluation set}

The evaluation set taken in the comprehensive evaluation of the interval approximation of the tourist road is listed as follows:

$$
\mathrm{V}=\{\text { excellent(v1)good(v2)medium(v3)inferior(v4)poor(v5) }\}
$$




\subsubsection{Establishment of a set of factors}

According to the idea of landscape harmony design, this paper establishes a set of evaluation factors for tourist road, proceeding from the three levels of road landscape function, environment and aesthetics. This paper divides the evaluation contents into three subsets: the harmony of road area, the harmony between people and road, the harmony of the external environment of the road, denoted as $U=\{U 1, U 2, U 3\}$. Ui represents a subset of the influencing factors in the $\mathrm{I}^{\text {th }}$ aspect of the tourist road, namely, the analytical and evaluation indicator. $\mathrm{U} 1=\{\mathrm{U} 11, \mathrm{U} 12, \mathrm{U} 13, \mathrm{U} 14, \mathrm{U} 15\}$, $\mathrm{U} 2=\{\mathrm{U} 21, \mathrm{U} 22, \mathrm{U} 23\}, \mathrm{U} 3=\{\mathrm{U} 31, \mathrm{U} 32, \mathrm{U} 33, \mathrm{U} 34, \mathrm{U} 35\}$. Uij indicates the $\mathrm{J}^{\text {th }}$ influence factor set in the $\mathrm{i}^{\text {th }}$ subset of the tourist road, which is the descriptive index.

\subsubsection{Determination of weight}

According to the entropy method, the weights of various evaluation factors for the harmony of tourist road are determined. The weights of the indicators are calculated for the harmonization of tourist road. See Table 4.-Table 7.

Table 4. Weights of indicators on the road area harmony of tourism road

\begin{tabular}{|c|c|c|c|c|c|}
\hline \multirow{2}{*}{$\begin{array}{c}\text { Harmony of road area } \\
\text { B1 }\end{array}$} & B11 & B12 & B13 & B14 & B15 \\
\cline { 2 - 6 } & 0.18 & 0.28 & 0.17 & 0.14 & 0.12 \\
\hline
\end{tabular}

Table 5. Weights of indicators for tourist road harmony

\begin{tabular}{|c|c|c|c|}
\hline Harmony between & B21 & B22 & B23 \\
\cline { 2 - 4 } people and road B2 & 0.4 & 0.4 & 0.2 \\
\hline
\end{tabular}

Table 6.Evaluation of the indicators of the external harmony of the tourist road

\begin{tabular}{|c|c|c|c|c|c|}
\hline $\begin{array}{c}\text { Harmony of the } \\
\text { external environment } \\
\text { B3 }\end{array}$ & B31 & B32 & B33 & B34 & B35 \\
\cline { 2 - 6 } & 0.139 & 0.114 & 0.302 & 0.302 & 0.143 \\
\hline
\end{tabular}

Table 7. Weight of the first level index of harmonious evaluation of tourist road

\begin{tabular}{|c|c|c|c|}
\hline $\begin{array}{c}\text { Tourist road } \\
\text { harmony evaluation } \\
\text { A }\end{array}$ & $\begin{array}{c}\text { harmony between } \\
\text { people and road }\end{array}$ & harmony of road area & $\begin{array}{c}\text { harmony of the external } \\
\text { environment }\end{array}$ \\
\cline { 2 - 4 } & 0.333 & 0.333 & 0.333 \\
\hline
\end{tabular}

\subsection{Evaluation of the harmony between people and road B2}

Take the harmony between people and road B2 as an example to evaluate. Assume I1= \{pavement comfort evaluation B21 $\}, \mathrm{I} 2=$ transport engineering evaluation B22 $\}, \mathrm{I} 3=$ \{evaluation of service area and observation deck B23\}. $\mathrm{c} 1=\{$ excellent $\}, \mathrm{c} 2=\{$ good $\}, \mathrm{c} 3=\{$ medium $\}$, c4 $=$ \{inferior $\}, \mathrm{c} 5=\{$ poor $\}$. Then establish the single index division of B2 (internal harmony of tourism road), as shown in Table 8. 
Table 8. Single index division of B2 (internal harmony of tourism road)

\begin{tabular}{|c|c|c|c|}
\hline & I1 & I2 & I3 \\
\hline C1 & $8.5-10$ & $4-5$ & $80-100$ \\
\hline C2 & $7-8.5$ & $3-4$ & $70-80$ \\
\hline C3 & $5.5-7$ & $2-3$ & $60-70$ \\
\hline C4 & $4-5.5$ & $1-2$ & $50-60$ \\
\hline C5 & $0-4$ & $0-1$ & $0-50$ \\
\hline
\end{tabular}

According to the road landscape survey concerning the harmony between people and road, interval estimation is adopted, to obtain the following data, as shown in Table 9.

Table 9. Survey data of the harmony between people and road

\begin{tabular}{|c|c|c|c|}
\hline & I1 & I2 & I3 \\
\hline Score & $7.7-8.4$ & $3.6-4.1$ & $69-78$ \\
\hline
\end{tabular}

(1) From tables 8 and 9, the decision matrix for evaluation of road harmony is obtained:

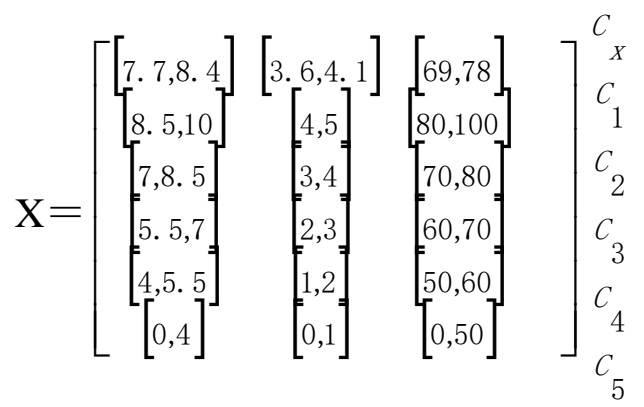

B21, B22, B23 belong to benefit index. After calculation, the normalized interval number decision matrix can be obtained:

$$
\mathrm{Y}=\left[\begin{array}{l}
{[0.166,0.246} \\
0.181,0.300 \\
0.158,0.240 \\
{[0.136,0.21}
\end{array}\right]\left[\begin{array}{l}
0.200,0.390 \\
0.113,0.180 \\
0.113,0.355 \\
0.000,0.150
\end{array}\right]\left[\begin{array}{l}
0.169,0.253 \\
0.146,0.284 \\
0.098,0.213 \\
0.197,0.310 \\
0.049,0.142 \\
0.000,0.071
\end{array}\right]\left[\begin{array}{l}
C_{X} \\
0.162,0.263 \\
0.127,0.217 \\
C_{1} \\
0.093,0.170 \\
0.000,0.124
\end{array}\right] C_{2}
$$

From the calculation of the weight, it can be seen that the attribute weight vector of the indicator concerning the harmony between tourist road and people is $\theta=(0.4,0.4$, and 0.2$)$, so that the decision-making evaluation matrix $\mathrm{R}$ is shown as follows:

$$
\left.\mathrm{R}=\left[\begin{array}{c}
{[0.068,0.103} \\
0.075,0.122 \\
0.062,0.104 \\
0.048,0.086 \\
0.035,0.067 \\
0.000,0.049
\end{array}\right]\left[\begin{array}{l}
0.075,0.121 \\
0.084,0.147 \\
0.063,0.118 \\
0.042,0.088 \\
0.021,0.059 \\
0.000,0.029
\end{array}\right]\left[\begin{array}{l}
0.032,0.047 \\
0.037,0.061 \\
0.032,0.047 \\
0.027,0.043 \\
0.023,0.036 \\
0.000,0.030
\end{array}\right]\right]_{C_{5}}
$$

(2) Calculate the distance between the set to be evaluated $\mathrm{Cx}$ and each indicator grade $\mathrm{Ci}$. The 
distance between the index set and each grade of harmony evaluation concerning the harmony between road and people can be obtained as follows: $d_{1}=0.0351, d_{2}=0.0134, d_{3}=0.0389, d_{4}=$ $0.0836, d_{5}=0.1188$.

(3) The minimum value of $d_{i}$ determines the evaluation level of the plan to be evaluated. As $d_{2}$ is the smallest value, the evaluation grade is good with regard to the harmony of roads and people.

(4) Interval estimation is adopted to convert the score value into percentage system, and the interval estimation of B2 is obtained $(73.4,82)$.

Adopt the same method to evaluate the harmony of road area, and harmony of the external environment. The evaluation grade is excellent. The score is transformed into the percentage system. The attribute weight vector is $\theta=(0.333,0.333,0.333)$, and the objective hierarchy decision evaluation matrix is obtained as follows:

$$
\left.\mathrm{R}=\left[\begin{array}{c}
{[0.055,0.082} \\
0.060,0.100 \\
0.053,0.080 \\
0.045,0.070 \\
0.038,0.060 \\
0.000,0.050
\end{array}\right]\left[\begin{array}{l}
0.067,0.130 \\
0.065,0.118 \\
0.049,0.094 \\
0.032,0.071 \\
0.016,0.047 \\
0.000,0.024
\end{array}\right]\left[\begin{array}{l}
0.056,0.086 \\
0.066,0.103 \\
0.054,0.088 \\
0.042,0.072 \\
0.031,0.057 \\
0.000,0.041
\end{array}\right]\right]_{C_{5}}^{C}
$$

(5) Finally, calculate the value of $d_{i}$ to determine the assessment level of the evaluation plan, which is to be evaluated. Then, the target rating is determined as excellent. Therefore, the evaluation grade is excellent concerning tourist road harmony, which has the same result as the evaluation of the project via analytic hierarchy process ${ }^{[10-15]}$. This further validates the appropriateness and practicality of the valuation for tourist road, based on interval approximation.

It is necessary to analyze why the evaluation level for the tourist road is excellent. It can be seen that the above-mentioned result is determined by the landscape evaluation of single indicators and individual evaluation standard, so the choice of monomial index is very important. Through empowerment and interval estimation, subjectivity can be eliminated to a certain degree. For this specific road, the interval of scoring value is excellent, good, and excellent respectively for the harmony of road area, the harmony between people and road, together with the harmony of the external environment of the road. It also show that in the evaluation of the harmony of tourist road based on interval number, the indicator value is evaluated by interval number, which can reflect the quality of the index objectively and avoid the problem of absoluteness.

\section{Conclusion}

1) The paper deeply studies the concept of tourism road harmony, and establishes the evaluation system of tourism road harmony, which takes the harmony of road area, the harmony between people and road, the harmony of the external environment of the road as the core evaluation indexes.

2) The evaluation method of tourism road harmony is put forward, based on interval approximation.

3) The interval approximation method pays more attention to the representativeness and objectivity of the landscape index, which makes the evaluation result intuitive and accurate, and improves its reliability. Through the evaluation of a tourist road, the practicability of the evaluation method based on interval approximation is further verified. 


\section{References}

[1] Department of Roads, Ministry of Transport, New Concept Road Design Guide, People's Communications Press, Beijing, p. 2-12,2005.

[2] Zhang Xiuli, Research on Road Landscape Evaluation, Doctoral Dissertation of Chang'an University, Xi'an, 2007.

[3] Smita M, Lee E.F., MalcolmT.J, Jim M, Examining the effect of alternative Management strategies on landscape-scale forest patterns in northeastern Minnesota using LANDIS, Ecological Modeling, p. 73-87,2004.

[4] Countryside Agency and Scottish Natural Heritage, Interim Landscape Character Assessment Guidance, UK Countryside Agency, Cheltenham, 1999.

[5] Gary R.Clay, Robert.K.S, Assessing the Validity and Reliablility of Descriptor Variables Used in Scenic Road Analysis, Landscape and Urban Planning, p.239-255, 2004.

[6] Chen Yuren, Zhu Zhaohong et al, Study on Road Environment Impact Assessment Index System, Journal of Tongji University (Natural Science), p.640-644, 1996.

[7] Wang Zhaohui, Wang Xuangcang et al. Comprehensive Evaluation of Pavement Performance Based on Interval Number Approximation Method. Journal of Road and Transportation Research and Development, p.21-24, 2009.

[8] Zhang Jijun, Fan Yuying. Approximation Ideal Point Method for Multi-criteria Decision- making Problems with Interval Weights. Systems Engineering and Electronics, p. 76 77,2002.

[9] Dang Yaoguo, Liu Sifeng et al. Research on Multi-indicator Interval Number Association Decision Model [J]. Journal of Nanjing University of Aeronautics and Astronautics, p. 403-406,2004.

[10] Yuan Chunyi. Research on Several Post-evaluation Issues for Road Development in China. Xi'an: Doctoral Dissertation of Chang'an University, 2009.

[11] Zhang Zhong, Xia Lei, Zhang Hao, Li Chengxiang. Comprehensive Evaluation of Airport Cement Concrete Pavement Performance Based on Multi-index Interval Approximation. Journal of Civil Aviation Flight University of China, p. 25-29.2018.

[12]Luo Yan. Teaching Research on Gradual Approximation. Theory and Practice of Contemporary Education, $p$. 57-59, 2017.

[13] Zhao Depeng. Evaluation of Tourist Highway Route Schemes in Mountain Areas of Cold Region, Master's Thesis of Harbin Institute of Technology, 2017.

[14] Sun Yunlong. Research on Landscape Design Method of Tourist Highway in Chishui River Valley. Technology of Highway and Transport. p. 129-132,2018.

[15]Yan Wei, Cheng Qian, Liu Yue, Tang Ning. Discussion on the New Mode of Ecological Environment Management and Control along the Tourist Highway, p. 74-75, 2018. 